\title{
Thermoacoustical Excess Properties of Binary Liquid Mixtures - A Comparative Experimental and Theoretical Study
}

\author{
M. Yasmin*, K.P. Singh, S. Parveen, M. Gupta and J.P. Shukla \\ Department of Physics, University of Lucknow, Lucknow-226007, India
}

(Received March 18, 2009)

\begin{abstract}
Specific heat ratio $(\gamma)$, pseudo-Grüneisen parameter $(\Gamma)$, heat capacity $\left(C_{p}\right)$ and effective Debye temperature $\left(\theta_{\mathrm{D}}\right)$ for binary system of tetrahydrofuran with o-cresol and methanol respectively, were calculated using the experimentally measured densities, velocities and viscosities of the pure liquids and their mixtures over the whole composition range and at $T=293,303,313 \mathrm{~K}$. The excess pseudo-Grüneisen parameter $\left(\Gamma^{\mathrm{E}}\right)$, excess molar isentropic compressibility $\left(K_{\mathrm{s}}^{\mathrm{E}}\right)$ and excess acoustic impedance $\left(Z^{\mathrm{E}}\right)$ were also calculated. The excess deviation functions have been correlated using Redlich-Kister polynomial equation. The observed values of the excess parameters plotted against the mole fraction of tetrahydrofuran have been explained on the basis of intermolecular interaction suggesting strong interaction in tetrahydrofuran + o-cresol than in tetrahydrofuran + methanol. Partial molar isentropic compressibility at infinite dilution and their excess values were calculated for each component. Sanchez theory, Goldsach-Sarvas volume fraction statistics, Sudgen's relation, Flory-Patterson-Rastogi and Brock and Bird model were used with the Aurebach relation to compute theoretically the values of ultrasonic velocities at varying temperatures. The velocity deviations were estimated in terms of average percentage deviations. Internal pressure for both the systems were calculated theoretically and discussed on the basis of relative applicability of the models in theoretical estimations. The isothermal compressibility $\left(k_{T}\right)$, for these binary mixtures were theoretically evaluated by using the Flory statistical theory and five hard sphere models and compared with the experimental values.
\end{abstract}

PACS numbers: 43.35.+d, 62.60.+v, 82.60.Lf

\section{Introduction}

The present work is a continuation of systematic experimental studies on thermodynamic and transport properties of binary mixtures of tetrahydrofuran (THF) with o-cresol and methanol, as these solvents have important application in chemical industry and molecular techno$\log y$.

Tetrahydrofuran is used as a solvent for polyvinyl chloride in printing inks, lacquers and adhesives, as well as an intermediate in the preparation of many industrial chemicals [1]. Tetrahydrofuran is an exceptionally useful solvent for reactions with organoalkali compounds [2].

o-cresol is mostly used as an intermediate for the production of pesticides, epoxy resins, dyes and pharmaceuticals, also as a component of disinfectants and cleaning agents. o-cresol is readily biodegradable and has a low bio- or geo-accumulation potential. In $90 \%$ of the uses, cresols are organic intermediates in manufacturing of phenolic and epoxy resins, plasticizers, herbicides, rubber and plastic antioxidants, dyes, deodorizing and odor-enhancing compounds, fragrances and pharmaceuticals [3].

Methanol, also known as methyl alcohol, carbinol, wood alcohol, wood naphtha or wood spirit, is a polar liquid at room temperature and is used as an antifreeze,

* corresponding author; e-mail: myasmin908@gmail.com solvent, fuel and as a denaturant for ethyl alcohol. It is also used for producing biodiesel via transesterification reaction. Methanol is a common laboratory solvent. The largest use of methanol by far, is in making other chemicals. About $40 \%$ of methanol is converted to formaldehyde and from there into products as diverse as plastics, plywood, paints, explosives and permanent press textiles.

The derived parameters such as specific heat ratio $(\gamma)$, pseudo-Grüneisen parameter $(\Gamma)$, heat capacity $\left(C_{p}\right)$ and effective Debye temperature $\left(\theta_{\mathrm{D}}\right)$ which can be estimated from the experimental data give more comprehensive information about the structural and interactional aspects of the mixture at the microscopic level. The values of excess parameters have been estimated to study the possibilities and extent of the disruption of self association among the methanol and o-cresol molecules and the breaking of dipole-dipole interaction in THF along with hydrogen bonding between oxygen of THF molecule and hydrogen of $-\mathrm{OH}$ group of the alcohol and cresol molecule in the binary mixtures of THF with methanol and o-cresol, respectively. The estimated values of excess pseudo-Grüneisen parameter $\left(\Gamma^{\mathrm{E}}\right)$, excess molar isentropic compressibility $\left(K_{\mathrm{s}}^{\mathrm{E}}\right)$ and excess acoustic impedance $\left(Z^{\mathrm{E}}\right)$ are fitted into Redlick-Kister type polynomial equation to estimate the binary coefficient and standard deviations.

The study of ultrasonic velocity in liquids is well established forexamining the nature of intermolecular and 
intramolecular interactions in liquid system. Therefore, the ultrasonic measurements in liquids and its variation with temperature provide detailed information regarding the properties of the medium such as absorption, compressibility, intermolecular forces, molecular interactions, chemical structure and the energies of the molecules in motion. Here ultrasonic velocities of liquid mixtures of tetrahydrofuran with o-cresol and methanol have been theoretically estimated by Aurebach relation in which the surface tension values have been theoretically calculated by various empirical, semiempirical and statistical models and theories such as Sanchez theory, Goldsach-Sarvas volume fraction statistics, Sudgen's relation, Flory-Patterson-Rastogi model and Brock and Bird model and are compared with the experimental values. The results have been discussed on the basis of average percentage deviation.

Internal pressure is the fundamental liquid property, which is the resultant of forces of attraction and repulsion between the constituents of liquids. As degree of cohesion differs from liquid to liquid, internal pressure provides useful information about the molecular interactions in the liquid systems. In the present work, various relations for estimation of internal pressure of liquids and liquid mixtures, e.g. thermodynamic relation, relation using empirical equations for $\alpha$ and $k_{T}$, relation based upon Buehler-Hirschfelder-Curtiss equation of state and relation based upon Flory statistical theory have been used. Thermodynamic relation has been considered as an experimental method because the parameters used in the equation have been calculated with the help of experimental values of density. Estimated values of internal pressure have been analyzed in light of various theories involved and compared in terms of average percentage deviation.

The isothermal compressibility $\left(k_{T}\right)$ of these binary mixtures were theoretically calculated in terms of pure components data by using Flory's theory and hard sphere models and the results were compared with the experimental values in terms of average percentage deviations.

\section{Theoretical analysis}

The previously measured experimental values of $\rho, u$ and $\eta[4]$ were used to calculate the values of different parameters.

\subsection{Thermoacoustical parameters}

The effective Debye temperature $\theta_{\mathrm{D}}$ can be evaluated by using the following expression [5]:

$$
\theta_{\mathrm{D}}=\frac{h}{k}\left\{\frac{9 N}{4 \pi V_{\mathrm{m}}\left[\left(\frac{1}{u_{l}^{3}}+\frac{2}{u_{t}^{3}}\right)\right]}\right\}^{1 / 3},
$$

where $u_{l}$ and $u_{t}$ are the propagation velocities for longitudinal and transverse modes, respectively. $V_{\mathrm{m}}$ is the molar volume and $h, k$ and $N$ are the Planck constant, Boltzmann's constant and Avogadro's number, respectively.
The two wave velocities may be expressed in terms of density $\left(\rho_{\mathrm{m}}\right)$, the instantaneous adiabatic compressibility $\left(k_{\mathrm{s}}\right)$ and Poisson's ratio $(\sigma)$ for liquids exhibiting the quasi-crystalline properties, as follows:

$$
\begin{aligned}
& \frac{1}{u_{l}^{3}}+\frac{2}{u_{t}^{3}}=\left(k_{\mathrm{s}} \rho_{\mathrm{m}}\right)^{3 / 2}\left\{\left[\frac{1+\sigma}{3(1-\sigma)}\right]^{3 / 2}\right. \\
& \left.\quad+2\left[\frac{2(1+\sigma)}{3(1-2 \sigma)}\right]^{3 / 2}\right\},
\end{aligned}
$$

where

$$
k_{\mathrm{s}}=k_{T}-\frac{T \alpha^{2} V_{\mathrm{m}}}{C_{p}}
$$

and $\alpha, k_{T}, C_{P}$ represent the coefficient of linear expansion, the isothermal compressibility and the specific heat at constant pressure, respectively.

Poisson's ratio can be obtained from the knowledge of the bulk modulus $K_{T}$ and the modulus of rigidity $G_{T}$, which arise from the change in lattice spacing corresponding to the solid-like character of the liquid. The Poisson ratio $[6,7]$ is given by

$$
\sigma=\frac{3 A-2}{6 A+2}
$$

and

$$
A=\frac{K_{T}}{G_{T}}=\frac{4}{3 \gamma},
$$

where $\gamma$ is specific heat ratio defined as

$$
\gamma=\frac{k_{T}}{k_{\mathrm{s}}} \text {. }
$$

The pseudo-Grüneisen parameter has been defined in terms of specific heat ratio as

$$
\Gamma=\frac{\gamma-1}{\alpha T} \text {. }
$$

\subsection{Excess parameters}

In order to substantiate the presence of interaction between the molecules, it is essential to study the excess parameters. Excess parameters, associated with a liquid mixture, are a quantitative measure of deviation in the behavior of the liquid mixture from ideality. The literature survey [8-10] reveals that most common way to evaluate the excess value of a given thermodynamic parameter is to use the equation

$$
A^{\mathrm{E}}=A_{\text {expt }}-\sum_{i} x_{i} A_{i},
$$

where symbols have their usual meaning.

\subsection{Redlich-Kister polynomial equation}

The composition dependences of the excess properties are correlated by the Redlich-Kister polynomial equation [11]:

$$
Y^{\mathrm{E}}=x_{1}\left(1-x_{1}\right) \sum_{i=1}^{5} a_{i}\left(2 x_{1}-1\right)^{i-1} \text {. }
$$

The values of the coefficient $a_{i}$ were calculated by method of least squares along with the standard deviation $\sigma\left(Y^{\mathrm{E}}\right)$. The coefficients $a_{i}$ are adjustable parameters for a better fit of the excess functions. 

lation

The standard deviation values were obtained from re-

$$
\sigma\left(Y^{\mathrm{E}}\right)=\left[\frac{\sum_{i=1}^{n}\left(Y_{\mathrm{expt}}^{\mathrm{E}}-Y_{\mathrm{cal}}^{\mathrm{E}}\right)^{2}}{n-p}\right]^{1 / 2},
$$

where $n$ is the number of experimental points, $p$ is the number of parameters, $Y_{\text {expt }}$ and $Y_{\text {cal }}$ are the experimental and calculated parameters, respectively.

\subsection{Partial molar isentropic compressibility}

Molar isentropic compressibility was calculated by the relation

$$
K_{\mathrm{s}}=-(\partial V / \partial P)_{\mathrm{s}}=V_{\mathrm{m}} k_{\mathrm{s}} .
$$

The partial molar compressibilities $\overline{K_{\mathrm{m}, 1}}$ of $\mathrm{THF}$ and $\overline{K_{\mathrm{m}, 2}}$ of o-cresol and methanol in these mixtures were calculated adopting the approach used earlier $[12,13]$ for the calculation of partial molar volumes. $\overline{K_{\mathrm{m}, 1}}$ and $\overline{K_{\mathrm{m}, 2}}$ are evaluated using the following relations:

$$
\begin{aligned}
& \overline{K_{\mathrm{m}, 1}}=K_{\mathrm{s}}^{\mathrm{E}}+K_{\mathrm{m}, 1}^{*}+x_{2}\left(\frac{\partial K_{\mathrm{s}}^{\mathrm{E}}}{\partial x_{1}}\right)_{T, p}, \\
& \overline{K_{\mathrm{m}, 2}}=K_{\mathrm{s}}^{\mathrm{E}}+K_{\mathrm{m}, 2}^{*}-x_{1}\left(\frac{\partial K_{\mathrm{s}}^{\mathrm{E}}}{\partial x_{1}}\right)_{T, P},
\end{aligned}
$$

where $K_{\mathrm{m}, 1}^{*}$ and $K_{\mathrm{m}, 2}^{*}$ are the molar isentropic compressibilities of pure components THF and o-cresol or methanol, respectively.

We are interested to evaluate the partial molar isentropic compressibility of THF at infinite dilution $\left(x_{1}=0\right)$ in o-cresol and methanol, respectively, and the partial molar isentropic compressibilities of o-cresol and methanol at infinite dilution $\left(x_{2}=0\right)$ in THF. Therefore, $\overline{K_{\mathrm{m}, 1}^{0}}$ is obtained by setting $x_{1}=0$, which leads to

$$
\overline{K_{\mathrm{m}, 1}^{0}}=K_{\mathrm{m}, 1}^{*}+\sum_{i=0}^{n} a_{i}(-1)^{i} .
$$

Similarly, setting $x_{2}=0$, leads to

$$
\overline{K_{\mathrm{m}, 2}^{0}}=K_{\mathrm{m}, 2}^{*}+\sum_{i=0}^{n} a_{i} .
$$

In Eqs. (14) and (15), $\overline{K_{\mathrm{m}, 1}^{0}}$ and $\overline{K_{\mathrm{m}, 2}^{0}}$ represent the partial molar isentropic compressibilities of THF at infinite dilution in o-cresol or methanol and the partial molar compressibilities of o-cresol or methanol at infinite dilution in THF, respectively.

Excess partial molar isentropic compressibilities at infinite dilution $\overline{K_{\mathrm{m}, i}^{E, \infty}}$ for each component in binary liquid mixtures were evaluated through relations

$$
\begin{aligned}
& \overline{K_{\mathrm{m}, 1}^{\mathrm{E}, \infty}}=\overline{K_{\mathrm{m}, 1}^{0}}-K_{\mathrm{m}, 1}^{*}, \\
& \overline{K_{\mathrm{m}, 2}^{\mathrm{E}, \infty}}=\overline{K_{\mathrm{m}, 2}^{0}}-K_{\mathrm{m}, 2}^{*} .
\end{aligned}
$$

\subsection{Ultrasonic velocity}

Here we have used five different models and relations for surface tension to predict the ultrasonic velocity theoretically. From the theoretically computed values of sur- face tension, we have calculated the ultrasonic velocity using Aurebach relation [14].

$$
u=\left(\frac{\sigma}{6.3 \times 10^{-4} \rho}\right)^{2 / 3} \text {. }
$$

Using the density measured over all composition range and ultrasonic velocity of pure liquids at 293, 303, and $313 \mathrm{~K}$, surface tension of the system under investigation has been calculated by using following theories and relations.

Sanchez relation [15] has been applied successfully to binary liquid mixtures to deduce the values of surface tension of liquid mixtures

$$
\sigma=\sum_{i}\left(x_{i} A_{i}^{1 / 2}\right)\left[\sum_{i} \frac{\left(\phi_{i} \rho_{i}\right)}{\left(\phi_{i} k_{T i}\right)}\right]^{1 / 2},
$$

where $k_{T i}, \rho_{i}, \phi_{i}$ and $x_{i}$ are the isothermal compressibilities, densities of pure liquids volume fraction and the mole fraction of the $i$-th component. $A_{i}$ is defined as

$$
A_{i}=\sigma_{i}^{2}\left(\frac{k_{T i}}{\rho_{i}}\right) \text {. }
$$

Goldsach and Sarvas [16] used the mole fraction and volume fraction statistics to obtain the following expression for the surface tension of non-electrolyte solutions and applied this equation to obtain surface tension of various organic liquid mixtures.

$$
\begin{aligned}
\sigma & =-\left(\frac{R T}{A}\right) \ln \left[x_{1} \exp \left(\frac{-\sigma_{1} A}{R T}\right)\right. \\
& \left.+x_{2} \exp \left(\frac{-\sigma_{2} A}{R T}\right)\right],
\end{aligned}
$$

where $A$ is the molar surface area.

According to Sudgen, assuming that parachor $\left[P_{i}\right]$ is additive with respect to mole number [17], $\sigma$ can be obtained for a binary mixture as

$$
\sigma=\left\{\left[P_{1}\right] \frac{x_{1}}{M_{1}}+\left[P_{2}\right] \frac{x_{2}}{M_{2}}\right\}^{4} \rho^{4},
$$

where $M_{i}$ is the molar mass of the pure component $i$ and $\rho$ is the density of mixture.

Patterson and Rastogi [18] have used Flory statistical theory (FST) to calculate surface tension which in turn is used to evaluate ultrasonic velocity in liquid mixtures. The following relation was used to calculate characteristic surface tension [14]:

$$
\sigma^{*}=k^{1 / 3} P^{* 2 / 3} T^{* 1 / 3},
$$

where $k, P^{*}$ and $T^{*}$ are the Boltzmann constant, characteristic pressure and temperature, respectively. Thus the surface tension of a liquid mixture is given by the relation

$$
\sigma_{m}=\sigma^{*} \tilde{\sigma}(\tilde{V}) .
$$

Starting from the work of Prigogine and Saraga the equation for reduced surface tension [19] is given by

$$
\tilde{\sigma}(\tilde{V})=M \tilde{V}^{-5 / 3}-\frac{\tilde{V}^{1 / 3}-1}{\tilde{V}^{2}} \ln \left(\frac{\tilde{V}^{1 / 3}-0.5}{\tilde{V}^{1 / 3}-1}\right),
$$

where $M$ is the fraction of nearest neighbors that a 
molecule loses on moving from the bulk of the liquid to the surface.

Another theoretical model we analyzed is due to Brock and Bird [17], which obtains the surface tension of pure components only from the values of critical parameters. Using a suggestion by Miller, Brock and Bird expression for a binary mixture is given by

$$
\sigma=P_{\mathrm{cm}}^{2 / 3} T_{\mathrm{cm}}^{1 / 3} Q\left(1-T_{\mathrm{r}}\right)^{11 / 9},
$$

where

$$
Q=0.1196\left[1+\frac{T_{\mathrm{br}} \ln \left(P_{\mathrm{cm}} / 1.01325\right)}{1-T_{\mathrm{br}}}\right]-0.279
$$

and $P_{\mathrm{cm}}, T_{\mathrm{cm}}, T_{\mathrm{br}}$ are the critical pressure, critical temperature and boiling temperature for the mixture.

\subsection{Internal pressure}

A number of relations can be utilized to estimate the internal pressure in pure liquids and liquid mixtures. Some of them are summarized here.

\subsubsection{Thermodynamical relation}

The relation among applied pressure $(P)$, molar volume $(V)$, temperature $(T)$ and molar internal energy $(U)$ is given by thermodynamic relation

$$
\left(\frac{\partial U}{\partial V}\right)_{T}=T\left(\frac{\partial P}{\partial T}\right)_{V}-P
$$

The isothermal internal energy-volume coefficient $(\partial U / \partial V)_{T}$ is often called internal pressure $\pi_{i}$. Since $\alpha=(1 / V)(\partial V / \partial T)_{p}$ and $k_{\mathrm{T}}=-(1 / V)(\partial V / \partial P)_{T}$, the above equation, for the pressure limiting to zero, can be written as

$$
\pi_{i}=\frac{\alpha T}{k_{T}} .
$$

\subsubsection{Relation using empirical equations for $\alpha$ and $k_{T}$}

From the empirical equations for thermal expansion coefficient $\alpha$ and isothermal compressibility $k_{T}$ [20] we get

$$
\pi_{i}=44.2 T^{4 / 3} u^{3 / 2} \rho .
$$

2.6.3. Relation based upon Buehler-Hirschfelder-Curtiss equation of state

With the help of equation proposed by Buehler et al. $[21,22]$ the internal pressure can be given as

$$
\pi_{i}=\frac{2^{1 / 6} R T}{2^{1 / 6} V-d N^{1 / 3} V^{2 / 3}},
$$

where $V$ is the molar volume, $d$ is the molecular diameter, $T$ is the absolute temperature and $R$ is the gas constant.

\subsubsection{Relation based upon Flory statistical theory}

Knowing the thermal expansion coefficient $\alpha$ and isothermal compressibility $k_{T}$ of pure liquid components, the values of $\alpha$ and $k_{T}$ for liquid mixture can be evaluated as

$$
(\alpha)_{\text {Flory }}=\frac{3\left(\tilde{V}^{1 / 3}-1\right)}{\left[1-3\left(\tilde{V}^{1 / 3}-1\right)\right] T}
$$

and

$$
\left(k_{T}\right)_{\text {Flory }}=\frac{(\alpha)_{\text {Flory } T \tilde{V}^{2}}}{P^{*}},
$$

where $\tilde{V}$ is the reduced volume, $T$ is the absolute temperature and $P^{*}$ is the characteristic pressure. Using the values of $\alpha$ and $k_{T}$ thus obtained, one can evaluate the internal pressure of the liquid mixture using the relation

$$
\pi_{i}=\frac{(\alpha)_{\text {Flory }} T}{\left(k_{T}\right)_{\text {Flory }}} .
$$

\subsection{Isothermal compressibility}

The values of isothermal compressibility $k_{T}$ for the binary mixtures were predicted by the equation based on Flory's statistical theory [23, 24] and five rigid sphere equations [25] based on various hard sphere models which are Thiele-Lebowitz model [26, 27], Thiele model [26], Guggenheim model [28], Carnahan-Starling model [29] and Hoover-Ree model [30]. The experimental $k_{T}$ values were calculated using the relation

$$
k_{T}=k_{\mathrm{s}}+T \alpha^{2} V / C_{p},
$$

where $C_{p}$ is the heat capacity.

\section{Results and discussion}

The calculated values of specific heat ratio $(\gamma)$, heat capacity $\left(C_{p}\right)$, effective Debye temperature $\left(\theta_{\mathrm{D}}\right)$ and pseudo-Grüneisen parameter $(\Gamma)$ for THF + o-cresol and $\mathrm{THF}+$ methanol mixture with mole fraction of THF $\left(x_{1}\right)$ at $T=293,303,313 \mathrm{~K}$ are given in Tables I and II, respectively. The values of coefficient $a_{i}$ evaluated using the method of least squares for both the mixtures are given in Table III along with the standard deviations $\sigma\left(Y^{\mathrm{E}}\right)$. The values of excess $\Gamma^{\mathrm{E}}, K_{\mathrm{s}}^{\mathrm{E}}$ and $Z^{\mathrm{E}}$ are plotted against the mole fraction of THF and are shown in Figs. 1 to 3 , respectively.

Tables I and II reveal that the values of specific heat ratio $(\gamma)$, pseudo-Grüneisen parameter $(\Gamma)$ and effective Debye temperature $\left(\theta_{\mathrm{D}}\right)$ decrease with increase in temperature for both the mixtures, whereas heat capacity $\left(C_{p}\right)$ increases as temperatures increases. It is also observed that these parameters are affected by changing the mole fraction of THF. $\Gamma, \theta_{\mathrm{D}}$ and $C_{p}$ vary almost linearly with composition. The values of $\gamma$ and $\Gamma$ increase on increasing the mole fraction of the component having higher molecular weight. However, non-linear variation of $\gamma$ with mole fraction has been observed for both the mixtures.

The nature and sign of excess functions can be explained in terms of the molecular interactions considering both the positive and negative contributions. It can be seen from Fig. 1 that the values of excess pseudo-Grüneisen parameter $\left(\Gamma^{\mathrm{E}}\right)$ are negative for both the binary mixtures which indicate the presence of specific intermolecular interaction through hydrogen bonding between the oxygen atom of tetrahydrofuran and hydrogen atom of o-cresol and methanol. The values of $\Gamma^{\mathrm{E}}$ increase with temperature, which suggests that there is an increase in strength of interaction with temperature in both the mixtures. The values are more negative for 
TABLE I

Specific heat ratio $(\gamma)$, pseudo-Grüneisen parameter $(\Gamma)$, heat capacity $\left(C_{p}\right)$ and effective Debye temperature $\left(\theta_{\mathrm{D}}\right)$ for $\mathrm{THF}+\mathrm{o}$-cresol mixture with mole fraction of THF $\left(x_{1}\right)$ at $T=293,303,313 \mathrm{~K}$.

\begin{tabular}{|c|c|c|c|c|}
\hline$x_{1}$ & $\gamma$ & $\Gamma$ & $\begin{array}{c}C_{p} \\
{\left[\mathrm{cal} \mathrm{mol}^{-1}\right]}\end{array}$ & $\begin{array}{l}\theta_{\mathrm{D}} \\
{[\mathrm{K}]}\end{array}$ \\
\hline \multicolumn{5}{|c|}{$T=293 \mathrm{~K}$} \\
\hline 0.0000 & 1.347 & 1.1803 & 222.091 & 79.175 \\
\hline 0.1434 & 1.351 & 1.1862 & 208.835 & 79.669 \\
\hline 0.2735 & 1.355 & 1.1873 & 195.246 & 79.451 \\
\hline 0.3921 & 1.359 & 1.1876 & 182.807 & 79.111 \\
\hline 0.4999 & 1.365 & 1.1927 & 171.010 & 78.554 \\
\hline 0.5999 & 1.373 & 1.2017 & 159.701 & 77.775 \\
\hline 0.6923 & 1.382 & 1.2115 & 149.068 & 76.809 \\
\hline 0.7778 & 1.393 & 1.2227 & 139.272 & 75.765 \\
\hline 0.8571 & 1.403 & 1.2354 & 130.314 & 74.693 \\
\hline 0.9310 & 1.413 & 1.2436 & 121.977 & 73.478 \\
\hline 1.0000 & 1.422 & 1.2452 & 113.738 & 71.848 \\
\hline \multicolumn{5}{|c|}{$T=303 \mathrm{~K}$} \\
\hline 0.0000 & 1.328 & 1.0724 & 236.845 & 77.632 \\
\hline 0.1434 & 1.330 & 1.0702 & 222.007 & 77.789 \\
\hline 0.2735 & 1.333 & 1.0674 & 207.170 & 77.409 \\
\hline 0.3921 & 1.335 & 1.0628 & 193.791 & 76.957 \\
\hline 0.4999 & 1.342 & 1.0672 & 180.513 & 76.168 \\
\hline 0.5999 & 1.349 & 1.0739 & 167.678 & 75.092 \\
\hline 0.6923 & 1.359 & 1.0832 & 155.724 & 73.891 \\
\hline 0.7778 & 1.369 & 1.0942 & 144.814 & 72.655 \\
\hline 0.8571 & 1.381 & 1.1091 & 135.004 & 71.491 \\
\hline 0.9310 & 1.397 & 1.1296 & 125.473 & 70.049 \\
\hline 1.0000 & 1.407 & 1.1359 & 117.181 & 68.669 \\
\hline \multicolumn{5}{|c|}{$T=313 \mathrm{~K}$} \\
\hline 0.0000 & 1.313 & 0.9705 & 245.530 & 74.219 \\
\hline 0.1434 & 1.313 & 0.9625 & 229.917 & 74.189 \\
\hline 0.2735 & 1.313 & 0.9548 & 215.633 & 74.056 \\
\hline 0.3921 & 1.317 & 0.9532 & 201.199 & 73.528 \\
\hline 0.4999 & 1.321 & 0.9546 & 188.179 & 73.019 \\
\hline 0.5999 & 1.328 & 0.9592 & 175.037 & 72.094 \\
\hline 0.6923 & 1.338 & 0.9702 & 162.089 & 70.868 \\
\hline 0.7778 & 1.349 & 0.9837 & 150.453 & 69.685 \\
\hline 0.8571 & 1.361 & 0.9994 & 139.843 & 68.481 \\
\hline 0.9310 & 1.376 & 1.0184 & 130.155 & 67.267 \\
\hline 1.0000 & 1.391 & 1.0396 & 121.309 & 66.032 \\
\hline
\end{tabular}

THF + o-cresol as compared to THF + methanol which implies that the intermolecular interaction is stronger in $\mathrm{THF}+\mathrm{o}$-cresol which may be due to the reason that phenoxide ion of o-cresol is stabilized to a greater extent through resonance as compared to hydroxide ion of methanol thus making the phenol more acidic in nature.
TABLE II

Specific heat ratio $(\gamma)$, pseudo-Grüneisen parameter $(\Gamma)$, heat capacity $\left(C_{p}\right)$ and effective Debye temperature $\left(\theta_{\mathrm{D}}\right)$ for THF + methanol mixture with mole fraction of THF $\left(x_{1}\right)$ at $T=293,303,313 \mathrm{~K}$.

\begin{tabular}{|c|c|c|c|c|}
\hline$x_{1}$ & $\gamma$ & $\Gamma$ & 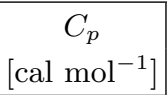 & $\begin{array}{l}\theta_{\mathrm{D}} \\
{[\mathrm{K}]}\end{array}$ \\
\hline \multicolumn{5}{|c|}{$T=293 \mathrm{~K}$} \\
\hline 0.0000 & 1.478 & 1.2558 & 41.283 & 77.511 \\
\hline 0.0471 & 1.472 & 1.2515 & 44.359 & 77.142 \\
\hline 0.1000 & 1.466 & 1.2469 & 47.815 & 76.664 \\
\hline 0.1599 & 1.460 & 1.2427 & 51.789 & 76.156 \\
\hline 0.2285 & 1.455 & 1.2392 & 56.392 & 75.583 \\
\hline 0.3075 & 1.449 & 1.2360 & 61.803 & 74.993 \\
\hline 0.3998 & 1.443 & 1.2343 & 68.230 & 74.347 \\
\hline 0.5090 & 1.438 & 1.2341 & 76.002 & 73.667 \\
\hline 0.6399 & 1.432 & 1.2335 & 85.709 & 73.072 \\
\hline 0.7995 & 1.427 & 1.2388 & 97.831 & 72.428 \\
\hline 1.0000 & 1.422 & 1.2452 & 113.738 & 71.848 \\
\hline \multicolumn{5}{|c|}{$T=303 \mathrm{~K}$} \\
\hline 0.0000 & 1.457 & 1.1470 & 43.119 & 75.295 \\
\hline 0.0471 & 1.451 & 1.1421 & 46.282 & 74.828 \\
\hline 0.1000 & 1.446 & 1.1381 & 49.856 & 74.293 \\
\hline 0.1599 & 1.440 & 1.1342 & 53.971 & 73.737 \\
\hline 0.2285 & 1.435 & 1.1307 & 58.710 & 73.087 \\
\hline 0.3075 & 1.430 & 1.1278 & 64.283 & 72.426 \\
\hline 0.3998 & 1.425 & 1.1261 & 70.876 & 71.690 \\
\hline 0.5090 & 1.420 & 1.1254 & 78.844 & 70.921 \\
\hline 0.6399 & 1.415 & 1.1254 & 88.735 & 70.194 \\
\hline 0.7995 & 1.411 & 1.1301 & 101.098 & 69.438 \\
\hline 1.0000 & 1.407 & 1.1359 & 117.181 & 68.669 \\
\hline \multicolumn{5}{|c|}{$T=313 \mathrm{~K}$} \\
\hline 0.0000 & 1.441 & 1.0560 & 44.662 & 72.668 \\
\hline 0.0471 & 1.434 & 1.0483 & 47.971 & 72.224 \\
\hline 0.1000 & 1.428 & 1.0430 & 51.690 & 71.698 \\
\hline 0.1599 & 1.423 & 1.0384 & 55.967 & 71.146 \\
\hline 0.2285 & 1.417 & 1.0343 & 60.934 & 70.550 \\
\hline 0.3075 & 1.412 & 1.0306 & 66.722 & 69.886 \\
\hline 0.3998 & 1.407 & 1.0277 & 73.575 & 69.153 \\
\hline 0.5090 & 1.402 & 1.0273 & 81.829 & 68.380 \\
\hline 0.6399 & 1.398 & 1.0282 & 92.043 & 67.633 \\
\hline 0.7995 & 1.395 & 1.0331 & 104.731 & 66.817 \\
\hline 1.0000 & 1.391 & 1.0396 & 121.309 & 66.032 \\
\hline
\end{tabular}

The values of excess molar isentropic compressibilities $\left(K_{\mathrm{s}}^{\mathrm{E}}\right)($ Fig. 2) for THF + o-cresol mixture are found to be negative over the entire composition range, which indicates that the mixture is less compressible than the corresponding ideal mixture. 


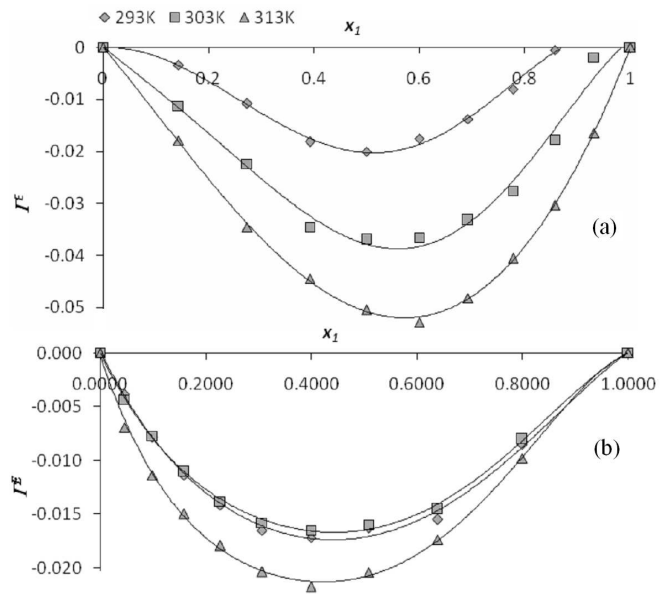

Fig. 1. (a) Excess pseudo-Grüneisen parameter $\left(\Gamma^{\mathrm{E}}\right)$ vs. mole fraction of THF $\left(x_{1}\right)$ for binary mixture of THF + o-cresol at $T=293,303,313 \mathrm{~K}$. (b) Excess pseudo-Grüneisen parameter $\left(\Gamma^{\mathrm{E}}\right)$ vs. mole fraction of THF $\left(x_{1}\right)$ for binary mixture of $\mathrm{THF}+$ methanol at $T=293$, $303,313 \mathrm{~K}$.

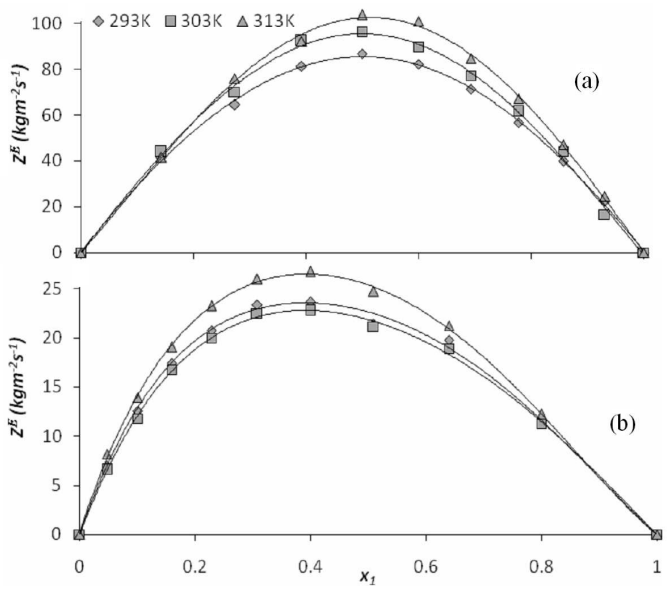

Fig. 2. (a) Excess acoustic impedance $\left(Z^{\mathrm{E}}\right)$ vs. mole fraction of THF $\left(x_{1}\right)$ for binary mixture of THF + o-cresol at $T=293,303,313 \mathrm{~K}$. (b) Excess acoustic impedance $\left(Z^{\mathrm{E}}\right)$ vs. mole fraction of THF $\left(x_{1}\right)$ for binary mixture of THF + methanol at $T=293,303$, $313 \mathrm{~K}$.

TABLE III

Adjustable parameters $a_{i}$ with the standard deviations $\sigma\left(Y^{\mathrm{E}}\right)$ for excess pseudo-Grüneisen parameter $\left(\Gamma^{\mathrm{E}}\right)$, excess acoustic impedance $\left(Z^{\mathrm{E}}\right)$, and excess molar isentropic compressibility for both the binary mixtures at temperature $T=293,303,313 \mathrm{~K}$.

\begin{tabular}{|c|c|c|c|c|c|c|c|}
\hline Parameters & $\begin{array}{c}\text { Temp. } \\
{[\mathrm{K}]}\end{array}$ & $a_{1}$ & $a_{2}$ & $a_{3}$ & $a_{4}$ & $a_{5}$ & $\sigma\left(Y^{\mathrm{E}}\right)$ \\
\hline \multicolumn{8}{|c|}{$\mathrm{THF}+\mathrm{o}$-cresol } \\
\hline \multirow[t]{3}{*}{$\Gamma^{\mathrm{E}}$} & 293 & -0.0869 & 0.0146 & 0.1673 & -0.0696 & -0.0427 & 0.0002 \\
\hline & 303 & -0.3575 & -0.9616 & -0.7325 & 1.9422 & 2.3316 & 0.0005 \\
\hline & 313 & -0.1995 & 0.0502 & -0.0141 & 0.0406 & 0.0400 & 0.0003 \\
\hline \multirow{3}{*}{$\begin{array}{l}Z^{\mathrm{E}} \times 10^{-3} \\
{\left[\mathrm{~kg} \mathrm{~m}^{-2} \mathrm{~s}^{-1}\right]}\end{array}$} & 293 & 346.8344 & -16.5097 & -143.2758 & 48.5663 & 225.4550 & 0.0813 \\
\hline & 303 & 349.2720 & -87.6560 & 224.0041 & 168.5739 & -403.8437 & 0.5701 \\
\hline & 313 & 438.3686 & 94.5512 & -66.5609 & -252.6640 & -161.5987 & 0.9488 \\
\hline \multirow{3}{*}{$\begin{array}{l}K_{\mathrm{s}}^{\mathrm{E}} \times 10^{14} \\
{\left[\mathrm{~m}^{5} \mathrm{~N}^{-1} \mathrm{~mol}^{-1}\right]}\end{array}$} & 293 & -243.4063 & 69.4389 & 64.0032 & -11.3557 & -149.3610 & 0.0482 \\
\hline & 303 & -281.2110 & 163.1849 & -279.7280 & -127.0632 & 407.8124 & 0.4020 \\
\hline & 313 & -375.0642 & 122.1414 & 45.7887 & 26.7855 & -59.3857 & 0.6200 \\
\hline \multicolumn{8}{|c|}{ THF + methanol } \\
\hline \multirow[t]{3}{*}{$\Gamma^{\mathrm{E}}$} & 293 & -0.0650 & 0.0030 & -0.0485 & -0.0773 & 0.1119 & 0.0001 \\
\hline & 303 & -0.0639 & 0.0038 & 0.0036 & -0.0626 & 0.0107 & 0.0001 \\
\hline & 313 & -0.0822 & -0.0191 & 0.0063 & -0.0524 & -0.0306 & 0.0001 \\
\hline \multirow{3}{*}{$\begin{array}{l}Z^{\mathrm{E}} \times 10^{-3} \\
{\left[\mathrm{~kg} \mathrm{~m}^{-2} \mathrm{~s}^{-1}\right]}\end{array}$} & 293 & 86.1901 & 29.4571 & 144.3472 & 98.5734 & -221.5526 & 0.1308 \\
\hline & 303 & 85.0160 & 29.1736 & 90.0909 & 60.7908 & -126.1915 & 0.1806 \\
\hline & 313 & 99.1479 & 22.9216 & 10.0370 & 65.0723 & 8.1809 & 0.0428 \\
\hline \multirow{3}{*}{$\begin{array}{l}K_{\mathrm{s}}^{\mathrm{E}} \times 10^{14} \\
{\left[\mathrm{~m}^{5} \mathrm{~N}^{-1} \mathrm{~mol}^{-1}\right]}\end{array}$} & 293 & 21.1589 & -5.1153 & -125.9916 & -88.0336 & 202.5821 & 0.1175 \\
\hline & 303 & 19.7142 & -6.0429 & -87.7291 & -60.9595 & 134.0959 & 0.1803 \\
\hline & 313 & 0.4054 & 0.5945 & -4.7450 & -74.6267 & -6.1099 & 0.0497 \\
\hline
\end{tabular}

The values of $K_{\mathrm{s}}^{\mathrm{E}}$ increase with temperature, suggesting an increase in intermolecular interaction between the unlike molecules due to thermal energy. However, the excess molar isentropic compressibilities for THF + methanol mixture are slightly negative in methanol rich region, turning to small positive values in THF rich region in observed temperature range. This indicates that dispersive forces are also operating in case of THF + methanol, in THF rich region.

Specific acoustic impedance is a quantity, which depends on the molecular packing of the systems. Excess acoustic impedance $\left(Z^{\mathrm{E}}\right)$ is positive for THF + o-cresol and THF + methanol mixtures and the values increase with increase in temperature. The positive values of $Z^{\mathrm{E}}$ 

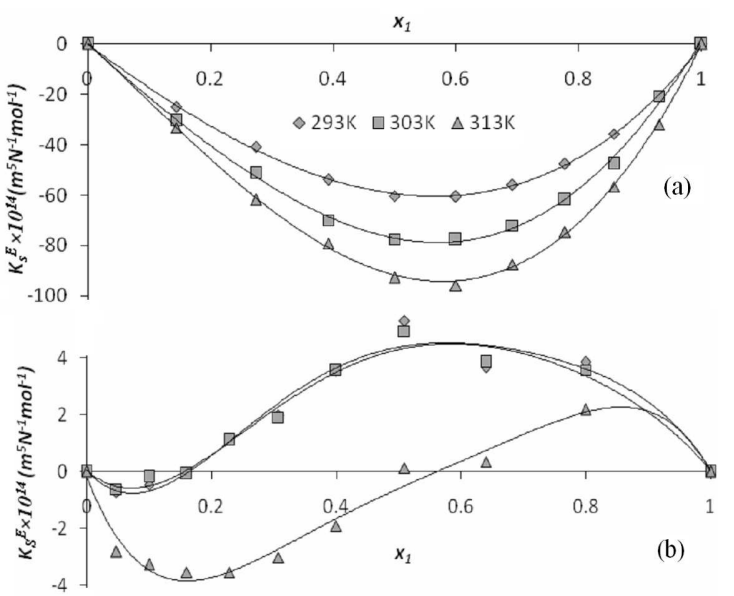

Fig. 3. (a) Excess molar isentropic compressibility $\left(K_{\mathrm{s}}^{\mathrm{E}}\right)$ vs. mole fraction of THF $\left(x_{1}\right)$ for binary mixture of THF + o-cresol at $T=293,303,313 \mathrm{~K}$. (b) Excess molar isentropic compressibility $\left(K_{\mathrm{s}}^{\mathrm{E}}\right)$ vs. mole fraction of THF $\left(x_{1}\right)$ for binary mixture of THF + methanol at $T=293,303,313 \mathrm{~K}$.

TABLE IV

Molar isentropic compressibility of pure liquids $\left(K_{\mathrm{m}, i}^{*}\right)$, partial molar isentropic compressibility $\left(\overline{K_{\mathrm{m}, i}^{0}}\right)$ and excess partial molar isentropic compressibility $\left(\overline{K_{\mathrm{m}, i}^{E, \infty}}\right)$ at infinite dilution of each component in $\mathrm{THF}+\mathrm{O}$-cresol and THF + methanol mixtures at varying temperatures.

\begin{tabular}{c|c|c|c|c|c|c|c}
\hline \hline Temperature & $K_{\mathrm{m}, 1}^{*}$ & $K_{\mathrm{m}, 2}^{*}$ & $\overline{K_{\mathrm{m}, 1}^{0}}$ & $\overline{K_{\mathrm{m}, 2}^{0}}$ & $\overline{K_{\mathrm{m}, 1}^{\mathrm{E}, \infty}}$ & $\overline{K_{\mathrm{m}, 2}^{\mathrm{E}, \infty}}$ \\
\hline \multicolumn{8}{c}{$\mathrm{THF}+$ o-cresol } \\
\hline $293 \mathrm{~K}$ & 5.3201 & 4.0475 & 1.4516 & 1.3407 & -3.8685 & -2.7068 \\
$303 \mathrm{~K}$ & 5.9218 & 4.2281 & 4.0293 & 3.0580 & -1.8925 & -1.1700 \\
$313 \mathrm{~K}$ & 6.4990 & 4.6857 & 1.1231 & 2.2884 & -5.3759 & -2.3973 \\
\hline \multicolumn{8}{c}{$\mathrm{THF}+$ methanol } \\
\hline $293 \mathrm{~K}$ & 5.3201 & 4.0622 & 7.2291 & 4.1082 & 1.9090 & 0.0460 \\
$303 \mathrm{~K}$ & 5.9218 & 4.3131 & 7.2526 & 4.3039 & 1.3308 & -0.0092 \\
$313 \mathrm{~K}$ & 6.4990 & 4.7064 & 7.1348 & 3.8616 & 0.6358 & -0.8448
\end{tabular}

suggest the presence of strong interaction through hydrogen bonding between oxygen atom of THF molecules with its lone pair of electron and the hydrogen atom of $-\mathrm{OH}$ group of alcohol and cresol. The positive values of $Z^{\mathrm{E}}$ in $\mathrm{THF}+$ o-cresol mixture are found to be approximately four times greater than $\mathrm{THF}+$ methanol mixture. This reflects the strong interaction in $\mathrm{THF}+\mathrm{o}$-cresol in comparison with THF + methanol which increases with temperature. The results of $\Gamma^{\mathrm{E}}, K_{\mathrm{s}}^{\mathrm{E}}$ and $Z^{\mathrm{E}}$ also support each other.

The values of $K_{\mathrm{m}, 1}^{*}, K_{\mathrm{m}, 2}^{*}, \overline{K_{\mathrm{m}, 1}^{0}}, \overline{K_{\mathrm{m}, 2}^{0}}, \overline{K_{\mathrm{m}, 1}^{\mathrm{E}, \infty}}$ and $\overline{K_{\mathrm{m}, 2}^{\mathrm{E}, \infty}}$ are listed in Table IV. These values can be interpreted in terms of structural compressibility, which results from the breakdown of associated structure on mixing of THF in alcohol and cresol as well as geomet-

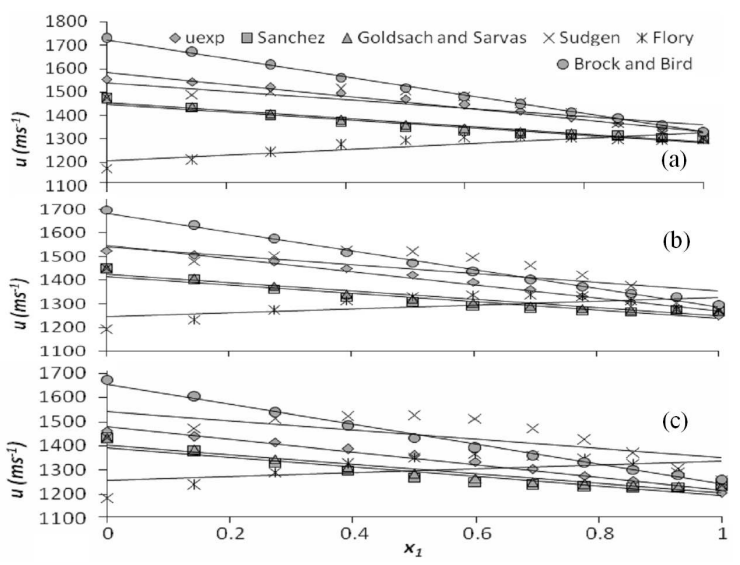

Fig. 4. (a) Comparison of the experimental and theoretically calculated velocities for the system THF + o-cresol at $293 \mathrm{~K}$. (b) Comparison of the experimental and theoretically calculated velocities for the system $\mathrm{THF}+$ o-cresol at $303 \mathrm{~K}$. (c) Comparison of the experimental and theoretically calculated velocities for the system THF + o-cresol at $313 \mathrm{~K}$.

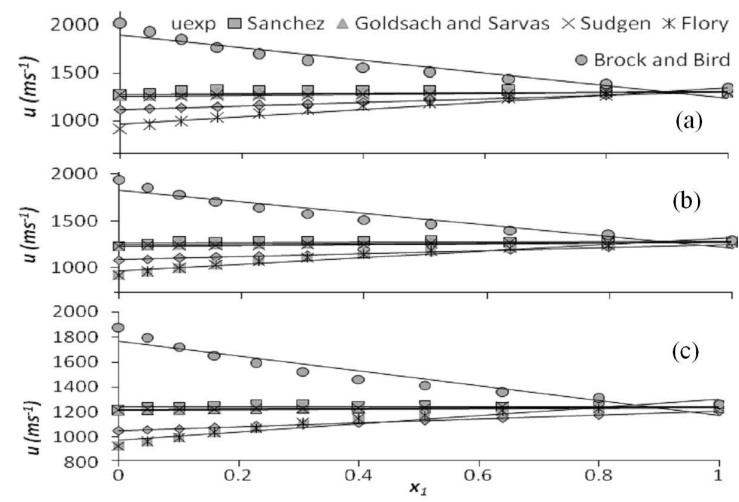

Fig. 5. (a) Comparison of the experimental and theoretically calculated velocities for the system THF + methanol at $293 \mathrm{~K}$. (b) Comparison of the experimental and theoretically calculated velocities for the system THF + methanol at $303 \mathrm{~K}$. (c) Comparison of the experimental and theoretically calculated velocities for the system $\mathrm{THF}+$ methanol at $313 \mathrm{~K}$.

TABLE V

Value of critical parameters for pure components.

\begin{tabular}{l|cc|c|c}
\hline \hline Parameters & \multicolumn{2}{|c|}{ THF } & o-cresol & methanol \\
\hline$\sigma\left[\mathrm{m} \mathrm{N} \mathrm{m}^{-1}\right]^{a}$ & $293 \mathrm{~K}$ & 26.40 & 37.41 & 22.46 \\
& $303 \mathrm{~K}$ & 25.12 & 36.40 & 21.69 \\
& $313 \mathrm{~K}$ & 23.84 & 35.39 & 21.69 \\
$T_{\mathrm{c}}[\mathrm{K}]^{b}$ & & 540.1 & 697.6 & 512.64 \\
$P_{\mathrm{c}}[\mathrm{MPa}]^{b}$ & & 5.19 & 5.01 & 8.09 \\
$T_{\mathrm{b}}[\mathrm{K}]^{b}$ & & 338 & 464.19 & 337.7 \\
$C_{p}\left[\mathrm{~J} \mathrm{~mol}{ }^{-1} \mathrm{~K}^{-1}\right]^{c}$ & $293 \mathrm{~K}$ & 141.4 & - & 81.30 \\
\hline
\end{tabular}

${ }^{a}$ calculated from the surface tension of Ref. [34]; ${ }^{b}[34] ;{ }^{c}[35]$ 
TABLE VI

Measured ultrasonic velocity and theoretical ultrasonic velocity of THF + o-cresol mixture from various methods and their average percentage deviations at $T=293,303,313 \mathrm{~K}$

\begin{tabular}{|c|c|c|c|c|c|c|}
\hline \multicolumn{7}{|c|}{$u_{\text {theo }}\left[\mathrm{m} \mathrm{s}^{-1}\right]$} \\
\hline$x_{1}$ & $u_{\exp }$ & Sanchez & G-Sarvas & Sudgen & Flory & B-Bird \\
\hline \multicolumn{7}{|c|}{$T=293 \mathrm{~K}$} \\
\hline 0.0000 & 1554.5 & 1471.9 & 1471.9 & 1471.9 & 1175.5 & 1728.2 \\
\hline 0.1434 & 1543.6 & 1433.2 & 1438.8 & 1489.8 & 1208.8 & 1669.8 \\
\hline 0.2735 & 1520.3 & 1399.8 & 1408.5 & 1503.1 & 1242.1 & 1614.8 \\
\hline 0.3921 & 1496.1 & 1370.7 & 1380.8 & 1512.9 & 1275.5 & 1562.8 \\
\hline 0.4999 & 1471.6 & 1349.5 & 1359.9 & 1504.7 & 1296.0 & 1519.0 \\
\hline 0.5999 & 1446.2 & 1334.6 & 1344.4 & 1481.1 & 1304.7 & 1481.3 \\
\hline 0.6923 & 1419.3 & 1323.6 & 1332.2 & 1449.9 & 1307.8 & 1447.3 \\
\hline 0.7778 & 1392.8 & 1316.0 & 1323.0 & 1412.2 & 1305.3 & 1416.7 \\
\hline 0.8571 & 1367.4 & 1311.6 & 1316.4 & 1369.0 & 1297.9 & 1389.3 \\
\hline 0.9310 & 1339.1 & 1306.4 & 1308.9 & 1332.0 & 1296.0 & 1360.9 \\
\hline 1.0000 & 1303.0 & 1300.5 & 1300.5 & 1300.5 & 1299.2 & 1331.8 \\
\hline $\mathrm{APD}$ & & 5.80 & 5.37 & 0.11 & 11.23 & -4.07 \\
\hline \multicolumn{7}{|c|}{$T=303 \mathrm{~K}$} \\
\hline 0.0000 & 1525.0 & 1447.9 & 1447.9 & 1447.9 & 1191.3 & 1696.3 \\
\hline 0.1434 & 1505.6 & 1400.9 & 1408.7 & 1481.4 & 1234.0 & 1631.9 \\
\hline 0.2735 & 1478.4 & 1362.6 & 1374.7 & 1504.2 & 1272.2 & 1573.6 \\
\hline 0.3921 & 1450.7 & 1328.2 & 1342.3 & 1527.3 & 1314.3 & 1517.3 \\
\hline 0.4999 & 1422.6 & 1306.0 & 1320.4 & 1519.2 & 1331.9 & 1473.3 \\
\hline 0.5999 & 1392.0 & 1289.8 & 1303.3 & 1497.3 & 1339.1 & 1434.7 \\
\hline 0.6923 & 1361.6 & 1278.5 & 1290.4 & 1464.4 & 1337.5 & 1400.8 \\
\hline 0.7778 & 1332.5 & 1271.0 & 1280.6 & 1424.0 & 1329.6 & 1370.5 \\
\hline 0.8571 & 1307.0 & 1268.1 & 1274.8 & 1373.9 & 1312.6 & 1344.5 \\
\hline 0.9310 & 1280.3 & 1272.8 & 1276.3 & 1304.6 & 1277.3 & 1326.2 \\
\hline 1.0000 & 1250.0 & 1268.4 & 1268.4 & 1268.4 & 1272.9 & 1298.1 \\
\hline $\mathrm{APD}$ & & 5.15 & 4.54 & -3.42 & 6.67 & -4.85 \\
\hline \multicolumn{7}{|c|}{$T=313 \mathrm{~K}$} \\
\hline 0.0000 & 1462.0 & 1429.7 & 1429.7 & 1429.7 & 1185.7 & 1671.4 \\
\hline 0.1434 & 1437.8 & 1376.5 & 1384.9 & 1472.5 & 1237.4 & 1601.4 \\
\hline 0.2735 & 1413.4 & 1330.9 & 1343.9 & 1510.4 & 1289.8 & 1536.0 \\
\hline 0.3921 & 1386.2 & 1296.9 & 1312.2 & 1524.0 & 1324.9 & 1481.5 \\
\hline 0.4999 & 1362.0 & 1269.4 & 1285.1 & 1526.8 & 1353.1 & 1432.5 \\
\hline 0.5999 & 1333.4 & 1249.2 & 1264.0 & 1511.5 & 1367.1 & 1390.4 \\
\hline 0.6923 & 1303.7 & 1238.0 & 1251.0 & 1471.3 & 1358.8 & 1357.2 \\
\hline 0.7778 & 1276.8 & 1230.8 & 1241.3 & 1423.2 & 1343.4 & 1327.8 \\
\hline 0.8571 & 1251.4 & 1227.5 & 1234.9 & 1367.8 & 1321.1 & 1302.0 \\
\hline 0.9310 & 1228.0 & 1228.7 & 1232.6 & 1303.6 & 1290.0 & 1280.4 \\
\hline 1.0000 & 1205.9 & 1233.7 & 1233.7 & 1233.7 & 1252.6 & 1262.2 \\
\hline $\mathrm{APD}$ & & 3.64 & 2.95 & -7.69 & 1.83 & -6.53 \\
\hline
\end{tabular}

rical compressibility which is due to simultaneous compression of the molecules leading to contraction in volume and decrease in the average intermolecular distances due to the formation of hydrogen bond between unlike molecules. It is observed from Table IV that the partial molar isentropic compressibility of THF at infinite dilution $\overline{K_{\mathrm{m}, 1}^{0}}$ in o-cresol and o-cresol at infinite dilution $\overline{K_{\mathrm{m}, 2}^{0}}$ in THF are smaller than the corresponding molar isentropic compressibility $K_{\mathrm{m}, 1}^{*}$ and $K_{\mathrm{m}, 2}^{*}$ of THF and o-cresol, respectively. It can also be observed that
TABLE VII

Measured ultrasonic velocity and theoretical ultrasonic velocity of THF + methanol mixture from various methods and their average percentage deviations at $T=293,303,313 \mathrm{~K}$.

\begin{tabular}{|c|c|c|c|c|c|c|}
\hline \multicolumn{7}{|c|}{$u_{\text {theo }}\left[\mathrm{m} \mathrm{s}^{-1}\right]$} \\
\hline$x_{1}$ & $u_{\exp }$ & Sanchez & G-Sarvas & Sudgen & Flory & B-Bird \\
\hline \multicolumn{7}{|c|}{$T=293 \mathrm{~K}$} \\
\hline 0.0000 & 1116.0 & 1261.4 & 1261.4 & 1261.4 & 919.4 & 2012.6 \\
\hline 0.0471 & 1127.4 & 1287.4 & 1270.1 & 1260.2 & 954.2 & 1925.0 \\
\hline 0.1000 & 1138.6 & 1304.0 & 1277.3 & 1260.7 & 996.4 & 1842.5 \\
\hline 0.1599 & 1150.8 & 1313.8 & 1283.0 & 1263.0 & 1038.4 & 1765.5 \\
\hline 0.2285 & 1164.1 & 1318.8 & 1287.5 & 1266.5 & 1078.2 & 1694.8 \\
\hline 0.3075 & 1178.9 & 1320.6 & 1291.5 & 1270.6 & 1118.6 & 1623.8 \\
\hline 0.3998 & 1195.8 & 1319.9 & 1294.8 & 1274.7 & 1156.0 & 1559.1 \\
\hline 0.5090 & 1215.2 & 1316.9 & 1296.4 & 1281.1 & 1190.8 & 1502.6 \\
\hline 0.6399 & 1238.7 & 1311.3 & 1297.5 & 1290.3 & 1232.4 & 1438.2 \\
\hline 0.7995 & 1267.6 & 1307.1 & 1299.8 & 1293.2 & 1263.6 & 1385.5 \\
\hline 1.0000 & 1303.0 & 1300.5 & 1300.5 & 1300.5 & 1299.2 & 1331.8 \\
\hline $\mathrm{APD}$ & & -9.89 & -8.32 & -7.26 & 6.74 & -39.21 \\
\hline \multicolumn{7}{|c|}{$T=303 \mathrm{~K}$} \\
\hline 0.0000 & 1084.0 & 1233.1 & 1233.1 & 1233.1 & 922.7 & 1938.8 \\
\hline 0.0471 & 1093.6 & 1256.4 & 1240.1 & 1234.1 & 955.4 & 1855.9 \\
\hline 0.1000 & 1103.8 & 1271.6 & 1246.5 & 1234.6 & 994.8 & 1778.8 \\
\hline 0.1599 & 1115.0 & 1280.2 & 1251.2 & 1237.7 & 1035.1 & 1706.1 \\
\hline 0.2285 & 1126.7 & 1284.3 & 1255.0 & 1241.6 & 1072.9 & 1639.5 \\
\hline 0.3075 & 1140.1 & 1285.8 & 1258.5 & 1245.5 & 1110.8 & 1572.7 \\
\hline 0.3998 & 1155.0 & 1285.0 & 1261.5 & 1249.3 & 1145.6 & 1511.7 \\
\hline 0.5090 & 1172.2 & 1281.8 & 1262.8 & 1255.8 & 1178.4 & 1458.1 \\
\hline 0.6399 & 1193.1 & 1277.3 & 1264.5 & 1262.1 & 1214.8 & 1398.0 \\
\hline 0.7995 & 1219.0 & 1273.7 & 1266.9 & 1263.9 & 1242.6 & 1348.4 \\
\hline 1.0000 & 1250.0 & 1268.4 & 1268.4 & 1268.4 & 1272.9 & 1298.1 \\
\hline $\mathrm{APD}$ & & -10.82 & -9.31 & -8.65 & 4.24 & -39.37 \\
\hline \multicolumn{7}{|c|}{$T=313 \mathrm{~K}$} \\
\hline 0.0000 & 1050.0 & 1213.2 & 1213.2 & 1213.2 & 928.1 & 1877.8 \\
\hline 0.0471 & 1058.3 & 1232.0 & 1215.8 & 1219.5 & 959.6 & 1795.1 \\
\hline 0.1000 & 1067.6 & 1244.4 & 1219.3 & 1221.0 & 997.2 & 1720.2 \\
\hline 0.1599 & 1078.0 & 1250.8 & 1222.0 & 1223.5 & 1035.4 & 1650.2 \\
\hline 0.2285 & 1089.5 & 1252.9 & 1223.6 & 1227.5 & 1072.3 & 1585.8 \\
\hline 0.3075 & 1101.9 & 1252.5 & 1225.3 & 1230.7 & 1109.2 & 1521.4 \\
\hline 0.3998 & 1115.6 & 1249.8 & 1226.3 & 1234.9 & 1144.0 & 1462.2 \\
\hline 0.5090 & 1132.0 & 1246.2 & 1227.2 & 1238.0 & 1173.8 & 1411.6 \\
\hline 0.6399 & 1152.0 & 1241.9 & 1229.1 & 1238.5 & 1204.9 & 1355.5 \\
\hline 0.7995 & 1176.1 & 1238.5 & 1231.8 & 1235.1 & 1227.9 & 1309.1 \\
\hline 1.0000 & 1205.9 & 1233.7 & 1233.7 & 1233.7 & 1252.6 & 1262.2 \\
\hline $\mathrm{APD}$ & & -11.89 & -10.33 & -10.72 & 1.21 & -39.61 \\
\hline
\end{tabular}

$\overline{K_{\mathrm{m}, i}^{\mathrm{E}, \infty}}$ have values in accordance with $K_{\mathrm{s}}^{\mathrm{E}}$ values for both the mixtures at each temperature. This further supports the presence of strong intermolecular interaction between unlike molecules and more pronounced interaction is observed in the mixture of THF + o-cresol as is also reflected from $\Gamma^{\mathrm{E}}, K_{\mathrm{s}}^{\mathrm{E}}$ and $Z^{\mathrm{E}}$ values.

The parameters for pure components used in the estimation of velocity theoretically are listed in Table V. 
TABLE VIII

Internal pressure of $\mathrm{THF}+\mathrm{o}$-cresol mixture from various methods at $T=293,303,313 \mathrm{~K}$.

\begin{tabular}{|c|c|c|c|c|}
\hline \multicolumn{5}{|c|}{$\pi_{i}\left[\times 10^{-5} \mathrm{~N} \mathrm{~m}^{-2}\right]$} \\
\hline$x_{1}$ & Eq. (29) & Eq. (30) & Eq. (31) & Eq. (34) \\
\hline \multicolumn{5}{|c|}{$T=293 \mathrm{~K}$} \\
\hline 0.0000 & 5544.7 & 5543.4 & 5544.7 & 364.2 \\
\hline 0.1434 & 5437.7 & 5436.4 & 5360.6 & 3788.3 \\
\hline 0.2735 & 5267.7 & 5266.4 & 5168.7 & 3928.2 \\
\hline 0.3921 & 5096.8 & 5095.6 & 4976.3 & 4064.4 \\
\hline 0.4999 & 4905.0 & 4903.9 & 4782.8 & 4175.5 \\
\hline 0.5999 & 4693.5 & 4692.4 & 4586.3 & 4264.3 \\
\hline 0.6923 & 4473.5 & 4472.4 & 4389.1 & 4339.4 \\
\hline 0.7778 & 4255.6 & 4254.6 & 4193.4 & 4401.0 \\
\hline 0.8571 & 4044.3 & 4043.4 & 3999.6 & 4449.8 \\
\hline 0.9310 & 3838.1 & 3837.2 & 3807.8 & 4503.6 \\
\hline 1.0000 & 3615.7 & 3614.8 & 3615.7 & 4560.9 \\
\hline APD & & -0.02 & -1.43 & -12.69 \\
\hline \multicolumn{5}{|c|}{$T=303 \mathrm{~K}$} \\
\hline 0.0000 & 5619.2 & 5617.8 & 5619.2 & 375.1 \\
\hline 0.1434 & 5488.5 & 5487.2 & 5416.6 & 3917.6 \\
\hline 0.2735 & 5306.1 & 5304.8 & 5207.1 & 4071.6 \\
\hline 0.3921 & 5131.2 & 5130.0 & 4997.9 & 4227.9 \\
\hline 0.4999 & 4913.1 & 4911.9 & 4785.2 & 4340.3 \\
\hline 0.5999 & 4671.6 & 4670.5 & 4569.0 & 4431.9 \\
\hline 0.6923 & 4426.3 & 4425.3 & 4352.7 & 4504.5 \\
\hline 0.7778 & 4188.3 & 4187.3 & 4138.6 & 4561.9 \\
\hline 0.8571 & 3963.7 & 3962.8 & 3927.6 & 4599.2 \\
\hline 0.9310 & 3716.6 & 3715.7 & 3715.6 & 4596.2 \\
\hline 1.0000 & 3510.3 & 3509.5 & 3510.3 & 4644.4 \\
\hline $\mathrm{APD}$ & & -0.02 & -1.31 & -8.81 \\
\hline \multicolumn{5}{|c|}{$T=313 \mathrm{~K}$} \\
\hline 0.0000 & 5457.5 & 5456.2 & 5457.5 & 382.5 \\
\hline 0.1434 & 5322.1 & 5320.9 & 5261.8 & 4011.8 \\
\hline 0.2735 & 5184.2 & 5183.0 & 5064.7 & 4195.0 \\
\hline 0.3921 & 4997.8 & 4996.6 & 4862.0 & 4345.4 \\
\hline 0.4999 & 4819.4 & 4818.3 & 4661.5 & 4481.0 \\
\hline 0.5999 & 4599.1 & 4598.0 & 4455.4 & 4589.1 \\
\hline 0.6923 & 4347.0 & 4346.0 & 4246.4 & 4655.6 \\
\hline 0.7778 & 4109.2 & 4108.2 & 4040.3 & 4705.1 \\
\hline 0.8571 & 3878.7 & 3877.7 & 3836.6 & 4736.3 \\
\hline 0.9310 & 3654.4 & 3653.6 & 3635.4 & 4744.7 \\
\hline 1.0000 & 3436.8 & 3435.9 & 3436.8 & 4733.4 \\
\hline $\mathrm{APD}$ & & -0.02 & -1.65 & -4.16 \\
\hline
\end{tabular}

TABLE IX

Internal pressure of THF + methanol mixture from various methods at $T=293,303,313 \mathrm{~K}$.

\begin{tabular}{|c|c|c|c|c|}
\hline \multicolumn{5}{|c|}{$\pi_{i}\left[\times 10^{-5} \mathrm{~N} \mathrm{~m}^{-2}\right]$} \\
\hline$x_{1}$ & Eq. (29) & Eq. (30) & Eq. (31) & Eq. (34) \\
\hline \multicolumn{5}{|c|}{$T=293 \mathrm{~K}$} \\
\hline 0.0000 & 2552.6 & 2552.0 & 2552.6 & 881.3 \\
\hline 0.0471 & 2623.4 & 2622.8 & 2647.1 & 8443.1 \\
\hline 0.1000 & 2694.9 & 2694.2 & 2743.2 & 8063.0 \\
\hline 0.1599 & 2771.8 & 2771.2 & 2841.5 & 7672.0 \\
\hline 0.2285 & 2853.1 & 2852.4 & 2941.2 & 7265.5 \\
\hline 0.3075 & 2943.4 & 2942.7 & 3044.5 & 6851.0 \\
\hline 0.3998 & 3040.8 & 3040.1 & 3150.6 & 6418.3 \\
\hline 0.5090 & 3149.4 & 3148.7 & 3259.7 & 5970.6 \\
\hline 0.6399 & 3284.2 & 3283.4 & 3374.0 & 5524.6 \\
\hline 0.7995 & 3431.3 & 3430.5 & 3491.7 & 5045.8 \\
\hline 1.0000 & 3615.7 & 3614.8 & 3615.7 & 4560.9 \\
\hline APD & & -0.84 & 1.28 & 103.88 \\
\hline \multicolumn{5}{|c|}{$T=303 \mathrm{~K}$} \\
\hline 0.0000 & 2553.2 & 2552.6 & 2553.2 & 908.7 \\
\hline 0.0471 & 2617.9 & 2617.3 & 2638.8 & 8702.3 \\
\hline 0.1000 & 2683.9 & 2683.3 & 2725.9 & 8300.1 \\
\hline 0.1599 & 2756.0 & 2755.3 & 2814.9 & 7891.2 \\
\hline 0.2285 & 2830.1 & 2829.4 & 2905.0 & 7466.1 \\
\hline 0.3075 & 2912.5 & 2911.8 & 2998.2 & 7031.7 \\
\hline 0.3998 & 3000.2 & 2999.5 & 3093.6 & 6579.7 \\
\hline 0.5090 & 3098.9 & 3098.1 & 3191.9 & 6115.4 \\
\hline 0.6399 & 3217.7 & 3217.0 & 3294.1 & 5646.0 \\
\hline 0.7995 & 3349.7 & 3348.9 & 3399.7 & 5149.2 \\
\hline 1.0000 & 3510.3 & 3509.5 & 3510.3 & 4644.4 \\
\hline APD & & -0.78 & 1.04 & 111.67 \\
\hline \multicolumn{5}{|c|}{$T=313 \mathrm{~K}$} \\
\hline 0.0000 & 2512.0 & 2511.4 & 2512.0 & 925.6 \\
\hline 0.0471 & 2579.8 & 2579.1 & 2595.2 & 8889.9 \\
\hline 0.1000 & 2645.7 & 2645.1 & 2679.4 & 8489.4 \\
\hline 0.1599 & 2716.6 & 2715.9 & 2765.5 & 8074.8 \\
\hline 0.2285 & 2792.5 & 2791.9 & 2853.0 & 7645.6 \\
\hline 0.3075 & 2873.1 & 2872.4 & 2943.1 & 7204.0 \\
\hline 0.3998 & 2959.4 & 2958.7 & 3035.4 & 6746.1 \\
\hline 0.5090 & 3053.4 & 3052.7 & 3130.3 & 6264.9 \\
\hline 0.6399 & 3164.7 & 3163.9 & 3228.7 & 5774.2 \\
\hline 0.7995 & 3285.8 & 3285.0 & 3330.1 & 5257.7 \\
\hline 1.0000 & 3436.8 & 3435.9 & 3436.8 & 4733.4 \\
\hline $\mathrm{APD}$ & & -0.87 & 0.66 & 119.63 \\
\hline
\end{tabular}


TABLE X

Experimental values and theoretically calculated values of isothermal compressibility $k_{T}$, by using Flory's theory and various hard sphere models at $T=293 \mathrm{~K}$ and average percentage deviations in the calculated values for binary mixture of THF + methanol mixture.

\begin{tabular}{c|c|c|c|c|c|c|c}
\hline \hline \multicolumn{6}{c}{$k_{T}\left[\times 10^{-10} \mathrm{~N}^{-1} \mathrm{~m}^{2}\right]$} \\
\hline$x_{1}$ & $k_{T \exp }$ & Flory & Thiele-Lebowitz & Thiele & Guggenheim & Carnahen-Starling & Hoover-Ree \\
\hline 0.0000 & 12.038 & 14.912 & 8.439 & 10.025 & 7.755 & 8.909 & 9.581 \\
0.0471 & 11.726 & 14.275 & 8.489 & 10.154 & 7.770 & 8.979 & 9.718 \\
0.1000 & 11.431 & 13.682 & 8.537 & 10.289 & 7.781 & 9.051 & 9.866 \\
0.1599 & 11.129 & 13.110 & 8.571 & 10.418 & 7.775 & 9.110 & 10.013 \\
0.2285 & 10.829 & 12.563 & 8.595 & 10.546 & 7.755 & 9.160 & 10.167 \\
0.3075 & 10.512 & 12.025 & 8.595 & 10.659 & 7.706 & 9.188 & 10.316 \\
0.3998 & 10.190 & 11.505 & 8.574 & 10.765 & 7.633 & 9.198 & 10.470 \\
0.5090 & 9.851 & 10.992 & 8.521 & 10.850 & 7.522 & 9.178 & 10.622 \\
0.6399 & 9.457 & 10.451 & 8.389 & 10.867 & 7.330 & 9.079 & 10.735 \\
0.7995 & 9.054 & 9.928 & 8.215 & 10.857 & 7.090 & 8.940 & 10.853 \\
1.0000 & 8.592 & 9.374 & 7.926 & 10.743 & 6.735 & 8.685 & 10.921 \\
APD & -15.21 & 18.39 & -2.54 & 27.36 & 12.46 & -0.17
\end{tabular}

A close perusal of Tables VI and VII reveals that Sudgen's and Goldsach-Sarvas's methods are in a fairly good agreement with the experimental values. Average percentage deviations in Flory, Brock and Bird and Sanchez methods are also within the limits of error. The parameter parachor $\left[P_{i}\right]$, introduced by Sudgen, has been calculated by using density thereby follows the same behavior. Earlier workers [31-33] also arrived at the same conclusion about Sudgen's method for evaluation of surface tension. Brock and Bird theory is found to give large deviations in case of THF + methanol in methanol rich region. Figures 4 and 5 are the graphical depiction of the ultrasonic velocities evaluated by various theories which show the relative deviations from the experimental values.

Internal pressures in the two binary mixtures have been computed using Eqs. (28) to (34). The computed values of internal pressure are depicted in Tables VIII and IX. It can be seen from these tables that internal pressure of $\mathrm{THF}+\mathrm{o}$-cresol mixtures is greater than that for THF + methanol. As far as various methods for estimating internal pressure in pure liquids and liquid mixtures are concerned, Eq. (34), based upon Flory statistical theory is found to give satisfactory results in case of THF $+\mathrm{o}-$ cresol where as it is found to give large deviations in case of THF + methanol. This may be due to the relation derived which is based upon some adjustments and the approach uses more than one empirical relations, which are not adjusted for methanol. The relation using empirical equations for $\alpha$ and $k_{T}$, based upon BuehlerHirschfelder-Curtiss equation of state, and the thermodynamic relation show good agreement with the experimental values for both the mixtures.

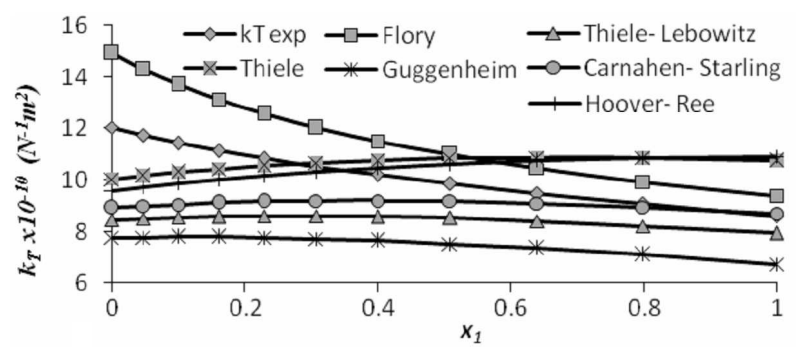

Fig. 6. Comparison of the experimental and theoretically calculated values of isothermal compressibilities for the system THF + methanol at $293 \mathrm{~K}$.

The experimental and predicted values of $k_{T}$ using Flory's statistical theory and five hard sphere models with average percentage deviations at $293 \mathrm{~K}$ are given in Table X. Flory's theory and five hard sphere models were compared with the experimental $k_{T}$ values. It is clear from the table that out of five hard sphere models the Hoover-Ree model predicts $k_{T}$ values the best in terms of average percentage deviations, followed by Thiele model, Carnahan-Starling model and Thiele-Lebowitz model while Guggenheim model could not predict $k_{T}$ values well. Figure 6 shows the relative variation of $k_{T}$ with the experimental values. It suggests that the values predicted by the Flory theory, Thiele model and Hoover-Ree model are near to the experimental values over the whole composition range.

\section{Conclusions}

The observed values of thermodynamic and excess parameters for both the mixtures show that the molecular 
interaction is stronger in the binary mixture of THF + o-cresol. Further the theories used for estimation of velocities show good agreement with the respective measured values of ultrasonic velocity, except the Brock and Bird theory, which gives large deviations for THF + methanol mixture. Various empirical and semi-empirical relations for theoretically predicting the internal pressure for binary mixtures give reasonably good result for both the mixtures. However, Buehler-HirschfelderCurtiss equation of state and the relation using empirical equations for $\alpha$ and $k_{T}$ are best suited for the prediction of internal pressure in both the mixtures. Models by Hoover-Ree and Thiele for evaluating the isothermal compressibility give very small deviations from the experimental values in comparison to the other models.

\section{Acknowledgments}

One of the authors (K.P. Singh) is grateful to UGC New Delhi for financial assistance.

\section{References}

[1] R.E. Kirk, D.F. Othmer, Encyclopedia of Chemical Technology, Vol. 10, Interscience, New York 1966, p. 237.

[2] J.F. Garst, in: Solute-Solvent Interactions, Eds. J.F. Coetzee, C.D. Ritchie, Marcel Dekker, New York 1969 , p. 539.

[3] OECD SIDS o-CRESOL, UNEP Publications.

[4] S. Parveen, D. Shukla, S. Singh, M. Gupta, J.P. Shukla, Appl. Acoust. 70, 507 (2009).

[5] M. Blackman, Encyclopedia of Physics 7, 328 (1955).

[6] C. Kittel, Introduction to Solid State Physics, Wiley, New York 1968.

[7] K.F. Herztold, T.A. Litovitz, Absorption and Dispersion of Ultrasonic Waves, Academic Press Inc., New York 1959

[8] J. Canosa, A. Rodriguez, J. Toju, J. Chem. Eng. Data 46, 846 (2001).

[9] F. Commelli, S. Ottani, R. Francesconi, C. Castellari, J. Chem. Eng. Data 47, 93 (2002).

[10] S.B. Alisha, M.C.S. Suba, K.C. Rao, J. Pure Appl. Ultrason. 23, 26 (2001).

[11] J.A. Riddick, W.B. Bunger, T.K. Sakana, Organic Solvents: Physical Properties and Methods of Purification, 4th ed., Wiley Interscience, New York 1986.
[12] S. Ottani, D. Vitalini, F. Comelli, C. Castellari, J. Chem. Eng. Data 47, 1197 (2002).

[13] H. Wang, W. Liu, J. Huang, J. Chem. Thermodynamics 36, 743 (2004).

[14] R. Aurebach, Experimentia 4, 473 (1948).

[15] I.C. Sanchez, J. Chem. Phys. 79, 405 (1984).

[16] D.E. Goldsach, C.D. Sarvas, Can. J. Chem. 59, 2968 (1981).

[17] R.C. Reid, J.M. Prausnitz, B.E. Poling, The Properties of Gases and Liquids, 4th ed., Mc Graw-Hill, New York 1976.

[18] D. Patterson, A.K Rastogi, J. Phys. Chem. 74, 1067 (1970).

[19] I. Prigogine, L. Saraga, J. Chem. Phys. 49, 399 (1952).

[20] J.D. Pandey, G.P. Dubey, N. Tripathi, J. Int. Acad. Phys. Sci. 1, 117 (1997).

[21] R.J. Buehler, R.H. Wentorff, J.O. Hirschfelder, C.F. Curtiss, J. Chem. Phys. 19, 61 (1951).

[22] J.O. Hirschfelder, C.F. Curtiss, R.B. Bird, Molecular Theory of Liquids, Wiley, New York 1954.

[23] P.J. Flory, J. Am. Chem. Soc. 87, 1833 (1965).

[24] A. Abe, P.J. Flory, J. Am. Chem. Soc. 87, 1838 (1965).

[25] A. Ali, A.K. Nain, D. Chand, B. Lal, Phys. Chem. Liquids 45, 79 (2007).

[26] E.J. Thiele, J. Chem. Phys. 39, 474 (1963).

[27] J.L. Lebowitz, H.L. Frisch, E.J. Helford, J. Chem. Phys. 51, 1037 (1969).

[28] E.A. Guggenheim, Mol. Phys. 9, 43 (1965).

[29] N.F. Carnahan, K.E. Starling, J. Chem. Phys. 51, 635 (1966).

[30] W.G. Hoover, E.H. Ree, J. Chem. Phys. 46, 4181 (1966).

[31] M.D. Perez, L. Segade, C. Franjo, O. Cabeza, E. Jiminez, Fluid Phase Equilib. 9, 232 (2005).

[32] E. Jiminez, M. Cabanas, L. Segade, S.G. Garbel, H. Casas, Fluid Phase Equilib. 180, 151 (2001).

[33] E. Rilo, S. Freire, L. Segade, O. Cabeza, C. Franjo, E. Jiminez, J. Chem. Thermodyn. 25, 839 (2003).

[34] D.L. Lide, CRC Handbook of Chemistry and Physics, 76th ed., CRC Press, USA 1995-96, p. 6-54, 155.

[35] J.F. Coetzee, T.H. Chang, Pure Appl. Chem. 57, 633 (1985). 